\title{
Obesity and Inflammatory Profile: Is Physical Exercise Able to Reverse This Process? A Mini Review
}

\author{
Tito Cardoso de Almeida Mafra, Christiane Salum Machado Simões, Marcus Vinicius Gomes Cezar Vieira, Lívia Ribeiro Borges \\ Lazzarotto, Juliana Cristina de Abreu Teixeira, Marco Aurelio Lopes Miranda, Adriana Antunes Vieira, André Abrantes Maciel \\ Ferreira, Marcos Renato Corrêa, Ismael Porto Bomfim, Débora Romualdo Lacerda and William Valadares Campos Pereira*
}

LACEF - Laboratório Científico da Educação Física. Faculdade Pitágoras de Belo Horizonte-Cidade Acadêmica. Rua Santa Madalena Sofia, 30 - Vila Paris, Belo Horizonte, 30380-000, MG, BR

${ }^{*}$ Corresponding author: William Valadares Campos Pereira, LACEF - Laboratório Científico da Educação Física. Faculdade Pitágoras de Belo Horizonte-Cidade Acadêmica. Rua Santa Madalena Sofia, 30 - Vila Paris, Belo Horizonte, 30380-000, MG, BR; Tel: 55+ 31 988129851; E-Mail: william.cpereira@kroton.com.br

Received: March 25, 2020; Accepted: April 03, 2020; Published: April 24, 2020

\begin{abstract}
Obesity represents a public health problem resulting from several factors. The studies highlighted the practice of physical exercise performed regularly, as a strategy to deal with overweight and obesity in different audiences. The present study aims to investigate the mechanisms of obesity advancement, mainly the installation and maintenance of low-grade systemic inflammation resulting from the development of obesity and to export the benefits of regular physical exercise practices for use and disease control. The search for scientific articles in the literature was carried out in the MEDLINE, PubMed, Scielo and Scholar Google databases. Among the articles researched, review studies, observations, clinical trials and consensus positions were considered. The research carried out included the main articles published between 2010 and 2019 and few with a longer publication period due to their relevance. The selected articles present relevant content for understanding the mechanisms by which obesity develops and the role of adipose tissue dysfunction in this process, in addition to studies that discuss the mechanisms by which physical exercise is able to promote the contribution of myocins and try to rebalance the inflammatory profile affected by obesity. It was concluded that muscle contraction resulting from physical exercise can release myocins that help to change the scenario of the inflammatory profile of obese and non - obese individuals, being a non-pharmacological tool in the treatment of obesity and other chronic diseases. The anti-inflammatory role of physical exercise needs to be further investigated.
\end{abstract}

Keywords: diabetes, Inflammation, Obesity, Overweight, Physical Exercise

\section{Introduction}

Obesity is a Chronic Non-Transmissible Disease (CNCD), understood as a multifactorial disorder that assumes the condition of an epidemic, affecting individuals of different age groups and with great prevalence in different countries of the world, having a great relationship with the emergence of several other diseases and high rates of morbidity and mortality [1,2]. The terms overweight and obesity are used to describe an excess of adiposity (or fat) above the ideal for good health. The use of anthropometric indicators, assist in the classification of cutoff points of the Body Mass Index (BMI), being used in the prediction of the weight status [3]. It is possible to point out several factors that can contribute to the development of obesity, among them are diets with positive caloric balance, physical inactivity, reduced basal metabolic rate, genetic and hereditary factors [4]. The interaction of these factors is complex and has been the focus of several studies. The increase in consumption of foods rich in sugars and fat and the decrease in the practice of physical exercises are the main factors related to the development of obesity [5]. The impacts that overweight and obesity have on the quality of life of children, adults and the elderly are the targets of several studies. The data found in the literature demonstrate significant reductions in quality of life, psychosocial health, self-esteem, emotional well-being, physical and functional capacities [6,7]. Current suggestions highlight the practice of regular physical exercise, an important strategy for coping with overweight and obesity, regardless of age. Organizations focused on public health care create guidelines that support these recommendations and provide a reference for professionals who deal directly and indirectly in the prevention, control and fight against obesity $[8,9]$.

It is known that Adipose Tissue (AT) is an organ with an important role in energy homeostasis, insulin sensitivity, angiogenesis, metabolism, inflammatory responses, immunity, endocrine and neuroendocrine systems $[7,8]$. Under conditions of overweight and obesity, it is common for endocrine and functional disorders to occur in adipocytes. In the opposite direction to sedentary lifestyle and obesity, studies have elucidated Physical Exercise (PE) can act to reduce harmful conditions associated with obesity [10]. The present study carried out a systematic review of the literature and aims to assist in understanding the progression of obesity in Brazilian society, the mechanisms involved in AT dysfunction and its low-grade, local or systemic chronic inflammation and physical exercise can modulate such an inflammatory cascade, thus helping to face this condition. 


\section{Results}

Initially 940 studies were found using the keywords previously mentioned. Initially, the exclusions took into account the relationship between the title of the articles and the proposed theme, leaving 126 articles, which after analyzing the summary and later reading in full, resulted in 52 articles that served as the basis for the production of this research. The other articles were excluded from the research due to their lack of relationship with the proposed theme. Of these, 12 studies investigate the understanding of the progression of obesity in modern society, 23 studies cover the mechanisms involved in the development of obesity and low- grade systemic inflammation and 17 discuss the benefits of PE to combat low- grade systemic inflammation.

\section{Discussion}

\section{The rise of obesity}

Obesity represents a public health problem with a major impact on the quality of life of affected individuals. Obesity is part of the group of Chronic Non-Communicable Diseases (NCDs), as well as diabetes, cancer, circulatory and cardiorespiratory diseases. Also according to data from the Ministry of Health, NCDs are the main causes of death in the world, corresponding to $63 \%$ of deaths in 2008 [11]. Obesity is defined as "an abnormal or excessive accumulation of fat, with possible damage to health" [12] and is related to a large number of disabilities and morbidity and mortality in several countries, in addition to being linked to the development of other pathologies such as resistance insulin, Cardiovascular Disease (CVD), type 2 Diabetes Mellitus (DM) and some types of cancer; being identified as a disease resulting from a conglomerate of factors. [1, 2]. In Brazil, this figure reaches $72 \%$ of the causes of death. The presence and maintenance of the condition of overweight and obesity generate great social, financial and family impact for the affected individuals. Treatment for obesity is costly to the public health sectors of various governments around the world. Several authors propose to discuss the real and updated costs of the disease to the public coffers and the Unified Health System (SUS). However, in addition to the values directly attributed to obesity, several other disorders and diseases are associated with the presence of obesity, considerably increasing the costs associated with the disease. According to Bahia, in a survey carried out between 2008 and 2010, the total values for procedures and treatments for overweight and obese people, were around 2.1 billion dollars annually in Brazil [9]. In 2015, a study promoted by the Ministry of Health and the National Supplementary Health Agency, through the Risk and Protection Factors Surveillance System for Chronic Diseases by Telephone Survey [13], carried out in 27 Brazilian cities, found that $52.3 \%$ of the adult population is overweight and among them, $17 \%$ are classified as obese. The costs to the public health system budget related to obesity and morbid obesity, in 2011, totaled US \$ 269.6 million, which corresponded to $1.86 \%$ of all Ministry of Health expenses with hospital and outpatient care. in Brazil [14].

It is evident that not only adults and the elderly suffer from this scenario, but also children and adolescents, which makes this an even more important topic to be discussed. Data from the World Health Organization (WHO) indicate that in 2016, almost 2 billion adults over 18 years of age were overweight, among them, more than half a billion were considered obese. As for individuals aged between 5 and 19 years old, the numbers also show a considerable increase, in 1975 only $1 \%$ of children and adolescents were classified as obese, whereas in 2016 , this percentage increased to $7 \%$ worldwide $[6,15]$. The understanding about obesity has evolved considerably in the last century, as well as the evaluation strategies for verifying the obesity condition itself. Among the possible examples of validated models, it is common to use anthropometric indicators, which help in the classification of the percentage of fat, as well as cut points of the Body Mass Index (BMI), which has been widely used in the prediction of the state of the body weight [3]. BMI classifications vary between results below 18.5, being classified as thin, 18.5 to 24.9 , normal BMI and defined overweight when the BMI reaches values between 25.0 to 29.9. The classification of obesity obeys class I with values between 30.0 - 34.9 of BMI; class II obesity, BMI values between 35.0-39.9; and obese class III, with BMI values above 40.0 [16].

Although the Body Mass Index (BMI) can be used to classify obesity in adults, its use in children and adolescents should not be used in isolation. Due to the need to take into account the variation in corpulence during growth, sex and age group [17]. In adults, body constitution should also be taken into account, due to variations in body mass, which can promote misinterpretations of BMI. The normal limit is established by percentile curves of the body mass index. Such values, which were updated in 2000 and are recognized by the World Health Organization $[18,19]$. As well as the definition of obesity exposed above, excessive accumulation of fat is usually referred to in the literature as a result of the relationship of several reasons. Tavares, et al. (2010) cites obesity as a multifactorial disease, resulting from the interaction of genetic, metabolic, social, behavioral and cultural factors, in addition to physical inactivity, which is referred to as one of the determining factors for the development and maintenance of the disease. Such notes are reinforced by other authors, such as SAHOO, who discusses the main factors that are commonly associated with theprogression of obesity, among them, diets with positive caloric balance, physical inactivity, reduced basal metabolic rate, genetic and hereditary factors $[4,17]$. The interaction of these factors is complex and has been the focus of several studies, however, the increase in the consumption of foods rich in sugars and fats and the decrease in the practice of physical exercises remain among the main factors related by scholars to the greater accumulation of fat and favoring the development and maintenance of obesity [5]. This accumulation comes from the ability to store fat, important for the survival of our species in past ages, however, it has become harmful in the face of the modern lifestyle, with a greater supply of foods rich in fat and lower levels of physical activity [20].

Although there are records of obese individuals who lived thousands of years ago, the disease epidemic in the modern age has become a more relevant public health problem, possibly due to the increasing life expectancy and the rise of NCDs. According to Francisqueti et al., obesity takes on the characteristics of a pandemic, due to the relationship with the emergence of other diseases. For the author, the inflammatory process inherent in the presence of obesity favors the development of cardiovascular diseases and insulin 
resistance [21]. Formerly it was thought that the function of TA was limited to the storage of fat, however, it is known today that adipocytes have a strong endocrine action. Under conditions of obesity, the secretion of cytokines and proteins is associated with the development of inflammatory processes. This concept is supported by the fact that obese individuals have high circulating levels of inflammation-related products [22] The maintenance of low-grade systemic inflammation in obese individuals is mentioned as one of the determining factors for the onset or development of several diseases, such as those previously mentioned. Resistance to the action of insulin, for example, may occur due to the damage that increased expression of the Tumor Necrosis Factor-alpha (TNF-a) offer the physiological action of insulin [23].

Several studies seek to elucidate the impacts that overweight and obesity cause on the quality of life of affected individuals. The findings available in the literature demonstrate significant reductions in quality of life, psychosocial health, self-esteem, emotional well-being, physical and functional capacities [24-26]. Obesity treatment strategies are very varied, including drug interventions, surgeries, dietary reeducation, among others. The regular practice of physical exercises has been recognized for years as an important factor for health promotion, however, recent research reinforces the discovery of the ability of physical exercise to promote the secretion of myokines, which contribute to the reduction of the inflammatory profile, being adopted as a non -pharmacological importance for the fight against obesity $[22,23,27]$ Therefore, physical exercise is an important modulator of the immune response. Current suggestions in the literature highlight the practice of physical exercise performed on a regular basis as an important strategy for coping with overweight and obesity in individuals of different age groups. Organizations focused on public health care create guidelines that support these recommendations and offer references for professionals who deal directly and indirectly in the prevention, control and fight against obesity $[6,18,19,28]$. However, although there are clear recommendations that encourage the practice of Moderate To Vigorous Physical Activity (MVPA) for at least 60 minutes daily [29], it is increasingly common that young people, adults and the elderly do not achieve the amount of daily physical activity recommended. A study carried out using questionnaires showed that $80.3 \%$ of adolescents between 13 and 15 years of age, do not reach recommended levels of MVPA worldwide. Phenomenon also observed in individuals of different age groups [30]. Innumerable factors can contribute for young people to practice physical activities or not, among them, socioeconomic, cultural, environmental issues, public policies, available infrastructure, food, relationship with parents and close people, physical self-concept and motor competence, season, body composition, among others. Such variables seem to have a great impact on the adherence of children and adolescents to the recommended practices of physical activity [30-32]. The practice of physical exercise during youth is reflected in adulthood, mainly in the level of physical activity performed, as well as in health and in the probability of developing diseases, such as obesity itself.

In addition to public policies that exhort about the value that the practice of physical activity has primarily on the health and quality of life of the population and that must be vehemently expanded and disseminated. It is extremely important that society fulfills its role as an encourager, support and practitioner, also creating adequate conditions for children, adolescents, adults and the elderly to practice physical activities regularly and comply with the goals suggested by current national and international guidelines [29, 32, 33]. It also contributes to the fight against several dysfunctions and diseases that are associated with a sedentary lifestyle. The appearance and progression of type 2 diabetes mellitus, hypertension, atherosclerosis and non-alcoholic liver steatosis, among other disorders and pathologies, make up the Metabolic Syndrome and are associated with AT dysfunction and sedentary lifestyle [34].

\section{Inflammatory Mechanisms Involved In the Development and Persistence of Obesity}

As mentioned above, overweight and obesity are recognized as a serious health risk factor, presenting a direct relationship with the appearance of several diseases, in addition to the premature death of millions of people each year. This phenomenon is recurrent mainly in developed and developing countries, such as the example used in Brazil $[16,22,35]$. It was previously thought that TA was a type of connective tissue with a restricted function of fat storage and mechanical protection for other tissues, however, the scientific literature has advanced in understanding this tissue. It is currently known that TA is an endocrine organ with autocrine and paracrine actions that are important in the regulation of metabolism, in the control of intake, in energy homeostasis, in the storage of fatty acids, among others. In conditions of obesity, TA is directly related to the development of resistance to the action of insulin in peripheral tissues such as skeletal muscle tissue and the liver. This condition favors the onset of Type 2 Diabetes Mélitus. The greater abundance of fatty acids also favors the appearance of heart diseases, especially with the formation of atheromatous plaques, characterized by the accumulation of fat on the wall of vessels and arteries. Several other diseases and some types of cancers are related to the presence of obesity and the disorders related to it [36].

Obesity is a multifactorial disease, and may derive from a conglomerate of conditions. It is common for the progression of the disease to occur as a result of a large supply of calories from the diet combined with a sedentary lifestyle, promoting an increase in the size and quantity of adipocytes [37]. It is believed that during the process of developing obesity, there is compression of the blood vessels that irrigate the adipocytes, by hypertrophied fat cells. It is possible that the anomaly in the function of these vessels impairs the supply of oxygen and other substances for adipose tissue. This process culminates in a cascade of events that lead to a condition called low-grade systemic inflammation $[34,36]$. Several mechanisms have been described in the literature as resulting from this anomaly. The affected tissue recruits cells from the immune system, such as m1-type macrophages and neutrophils, which attempt to reestablish homeostasis. The recruited macrophages migrate and infiltrate the AT, resulting in increased local production of pro-inflammatory cytokines, induction of the expression of pro-inflammatory factors and death of adipocytes. This condition of hypoxia of AT increases the expression of the Hypoxia Inducing Factor $1 \alpha$ (HIF-1a), which is related to the alteration of the expression of several genes, including Monocyte Chemotactic Protein 
1 (MCP-1) which promotes increased attraction of macrophages to adipocytes $[19,38,39]$.

The infiltration of M1-type macrophages in adipocytes favors tissue inflammation and is associated with altered release of several proteins and adipokines, which are important substances in the regulation of metabolism, immune system responses and in the control of several other organs and systems. Among the products secreted by adipocytes, we can highlight the increased expression of Leptin, which is a hormone with action in the hypothalamus, in addition to several other tissues. Leptin favors the control of intake and caloric balance, especially after feeding and also in a circadian manner. In conditions of obesity, it is possible that increased leptin secretion occurs, accompanied by dysfunction of its receptors, impairing caloric control and other homeostatic functions regulated by the hormone [39]. It is known that fat cells in the condition of obesity and cells of the immune system secrete the Tumor Necrosis Factor - Alpha (TNF-A) cytokine, and the genes that encode it are expressed in subcutaneous and visceral TA. TNF-A is associated with inflammation, apoptosis, cytotoxicity, production of other cytokines and induction of insulin resistance, mainly because it affects hormone receptors and reduces sensitivity to it. In addition to these factors, TNF-A also acts directly in several other processes, such as carbohydrate and lipid homeostasis; inhibition of lipogenesis and stimulation of lipolysis; and also in the formation of atheroma in blood vessel walls [40].

TNF-A promotes increased expression of several types of interleukins, including Interleukin-6 (IL-6) due to its important relationship with the regulation of innate and adaptive immune responses. This interleukin is produced by several immune cells and is increased in obesity. IL-6 is considered a pro-inflammatory factor and appears to inhibit the insulin signaling pathway through the positive regulation of SOCS3 gene expression, which promotes damage by favoring the phosphorylation of the insulin receptor protein (IRS1) preventing its interaction with the beta subunit of the insulin receptor and favoring the onset of Diabetes [41, 42]. In addition, IL-6 stimulates the production of Interferon-Gamma (INF-g), responsible for regulating positively a set of pro-inflammatory factors [43]. According to researcher Isabela Maia de Cruz, IL-6 may favor the increase in the production of C-Reactive Protein (CRP) by the liver. This protein is recognized for its pro-inflammatory function and is also commonly used as an acute phase inflammatory marker for individuals affected by different types of stress, injuries and pathologies, such as obesity itself [44]. CRP is also related to low back pain, especially in obese individuals.

Obese individuals are more likely to suffer from heart disease due to Angiotensinogen, which is synthesized primarily by the liver, but also abundantly by AT. According to LACERDA et al., 2016 [39], Angiotensinogen undergoes action of renin and angiotensin $I$ is converted, which in turn becomes angiotensin II through the Enzyme Angiotensin (ACE). Angiotensin II resulting from the production by obese TA stimulates the production of prostacyclins by adipocytes, which induce the differentiation of pre-adipocytes to functional adipocytes; favors the increase in blood pressure and the production of atheromatous plaques, due to the stimulation of the production of adhesion molecule- 1 and macrophage colony stimulating factor in the endothelial wall. Another important disorder occurs with the secretion of the hormone Resistin, which is directly related to insulin resistance in the muscle and liver for inducing the expression of endothelin-1 and thus contributing to endothelial dysfunction. In addition, resistin also favors a significant increase in the expression of VCAM- 1 and MCP-1, which play a decisive role in the formation of the initial atherosclerotic lesion, favoring the appearance of coronary lesions $[39,45]$. The high levels of TNF-a and IL-6 have, among other effects, a reduction in the synthesis and secretion of Adiponectin, an important adipokine with several anti- inflammatory and antiatherogenic actions. It reduces hepatic glucose production and improves insulin sensitivity in the liver and skeletal muscle; decreases serum glucose levels, free fatty acid triglycerides and the concentration of intracellular triglycerides; protective role against insulin resistance; modulates the activation of the transcription factor NF-kB (nuclear factor kappa beta), and the inflammatory response induced by TNF-a [42]. Adiponectin appears to inhibit TNF-a production and vice versa, in TA; therefore, adiponectin can indirectly inhibit the expression of IL- 6 and PCR by inhibiting the production of TNF-a. Adiponectin also induces the production of an important anti-inflammatory cytokine, Interleukin-10 (IL-10), and also causes the suppression of phagocytic capacity in macrophages and potentiates apoptosis in monocytes [23].

Although cytokines such as adiponectin and IL-10 play an important role in combating the development of obesity in the lowgrade systemic inflammation profile, it is known that pro-inflammatory cytokines contribute to the maintenance of inflammation and favor the expansion of obesity, causing changes in other systems, resulting in reduced satiety and increased demand for food, reduced metabolism and energy expenditure, decreased insulin sensitivity in the liver and skeletal muscle, increased hepatic glucose production and reduced oxidation of free fatty acids (AGL) [34, 46]. In contrast to the state of chronic inflammation of low local or systemic degree promoted by obese AT, it is known that EF plays an important role in combating the pro-inflammatory profile identified in obesity. New studies recognize the role of physical exercise in combating inflammation, according to KRINSKI et al., 2010, physical exercise is an important modulator of the immune response and function. The effects that justify this claim will be better addressed below [27].

\section{Anti-Inflammatory Action Triggered by Physical Exercise}

It is established in the scientific literature that the practice of physical exercises is important for the promotion and maintenance of health, due to positive adaptations, which include improvement in the lipid profile, decreased risk of developing obesity, diabetes mellitus 2 and cardiovascular diseases [44]. It is important to emphasize that not only the practice of physical exercises and the adequacy to recommended levels of weekly physical activities are important for health promotion, prevention and coping with various types of diseases, but insufficient physical activity routine is a risk factor important for the development of chronic diseases, especially those treated as Chronic Non-Communicable Diseases (DNCT), which include diabetes, hypertension, cardiovascular diseases and dyslipidemia. The term sedentary lifestyle is used to describe inactive behavior and the practice of activities that do not reach energy expenditure levels above 
rest levels. According to Meneguci and his collaborators, the effects of physical inactivity on health can be explained due to the fact that low muscle contraction is related to decreased use of glucose by muscles, increased insulin and lipids. These lipids are preferably stored in the AT of the visceral region, which contributes to the cascade of processes that leads to inflammation, as previously mentioned, and contributes to the development of chronic Non-Communicable Diseases (NCDs) $[47,48]$.

A study carried out at Universidade Estadual Paulista with Wistar rats initially submitted to a high-fat diet in order to develop obesity in animals, found development of resistance to the action of insulin and an inflammatory profile. After the resistance training protocol, there was an improvement in peripheral sensitivity to the action of insulin and a reduction in the expression of pro- inflammatory cytokines in the soleus muscle of rats exposed to a high-fat diet and resistance training. It is assumed that these changes also occur in several other tissues not evaluated. These findings can be justified by the positive adaptations in the oxidative capacity of the soleus muscle, contributing to the increase in the metabolism of lipids, resulting in a reduction in the transcription factors of pro- inflammatory cytokines and leading to an end to the improvement in insulin sensitivity and the responses of the imune system. The functioning of the immune system, in turn, is dependent on the communication between the nervous, endocrine and immune systems through peptide and neurotransmitter substances. Several studies have shown that the immune function can be modulated by physical exercise. Krinski and his collaborators (2010), explain that the stress caused by physical exercise induces changes in homeostasis control systems, influencing the immunoneuroendocrine axis, in addition to promoting changes in the levels of metabolic substrates [27].

However, the understanding of the relationship between physical exercise and the changes observed in the immune system is based on large studies carried out in the last two decades, until today. Technological advances in the fields of genetics and molecular biology provide analyzes that favor the understanding of the mechanisms involved between the practice of physical exercises and their influence on the immune system [29]. The effects of the practice of physical exercises previously mentioned on the various aspects of health that include the regulation of metabolism, glycemic control and insulin sensitivity, hypertension, immune responses and the fight against low-grade chronic inflammation, among others. They are currently recognized as a consequence of the action of myocins. According to Whitham and Febbraio, (2016), "myokines" are described as cytokines or peptides produced and released into the circulation by skeletal muscle cells due to their contraction. Myokines exert important endocrine or paracrine effects on other cells, tissues or organs. Therefore, it is possible to point out the skeletal muscle as an endocrine organ that communicates with several other systems [47].

As previously discussed in this study, sedentary lifestyle and obesity contribute to the development of several diseases due to the increased secretion of several pro-inflammatory cytokines. In contrast, myokines secreted by muscle cells stimulated by physical exercise seem to have a protective and antagonistic effect on pro- inflammatory adipokines from adipose cells [49]. Several machines are cataloged in the literature and their effects are widespread on different systems. Some myokines are highlighted due to practical knowledge of their effects on important health markers. Irisine, for example, is a type I membrane protein, secreted by skeletal muscle tissue after physical exercise. There is evidence that relate Irisin to the regulation of blood pressure and reduction of arterial hypertension, participation in mitochondrial biogenesis, darkening of white TA (Just like Meteorin-like 1) and improvement of obesity and glucose homeostasis. However, there may be controversies in understanding the role of irisin in heart disorders $[50,51]$.

The myokines that are currently best clarified is Interleukin-6. Unlike IL- 6 secreted by TA and associated with the development of an inflammatory profile and other disorders, IL- 6 secreted by the exercised skeletal muscle plays a different role. It is known that IL-6 as a myocin offers positive implications in several aspects, we can point out its function as an important activator of AMP-activated protein kinase (AMPK) in skeletal muscles, improving glucose uptake and insulin sensitivity; favoring lipolysis and oxidation of fatty acids in skeletal muscle; increased glucose tolerance, through the activation of glucagon as peptide 1 (GLP1) in the intestine, acting indirectly through GLP1 to reduce food intake and body weight [50]. It is possible that IL- 6 also acts as an anti -inflammatory and immunoregulatory myocin, this is due to the inhibition of TNF-a. This assumption starts from the observation of elevated levels of TNF-a in experiments carried out in knockout mice for IL-6. This suggests a negative regulation of TNF-a levels by IL- 6 . The anti-inflammatory effects of IL- 6 are also observed due to the stimulus that this cytokine promotes for the production of other anti-inflammatory cytokines, such as the interleukin-1 receptor antagonist (IL-1 ra) and the inhibitory factor of the synthesis of human cytokines IL-10 [49].

In addition to the metabolic effects, many of the myocins act directly within the skeletal muscle itself. Some examples include myostatin, LIF, IL-4, IL-6, IL-7 and IL-15, which, among other functions, regulate muscle hypertrophy and myogenesis. The regular practice of physical exercises, with consequent prolonged maintenance of the increase in circulating levels of IL-6, seems to promote improvement in the central communication of leptin and improvement of nutrient homeostasis, an important factor for the protection against diet-induced obesity and positive calorie balance. In addition, the IL-6 myocin is also related to improving metabolic homeostasis, with reduced insulin resistance promoted by a highfat diet in mice. There is evidence in the literature that indicates an important improvement in the metabolism of pancreatic $\beta$ cells and insulin secretion and an improvement in sensitivity to the hormone in several tissues $[38,49,52]$. Another important circulating factor induced in the exercised skeletal muscle is the meteorine-like protein (METRNL), which may be indirectly related to the stimulation of thermogenic genes, through the increase of eosinophils by the action of IL-4 and IL-13. These cytokines, in turn, cause changes in the macrophages in AT, with the adoption of the M2 type phenotype, which increases the expression of thermogenic and anti-inflammatory genes in AT. The increase in circulating METRNL levels is also related to stimulating energy expenditure and improving glucose tolerance 
[50]. The contraction of skeletal muscle through physical exercise, in addition to promoting increased production and release of several myokines, also modulates immune system responses, through cells such as monocytes, macrophages and neutrophils, in order to repair and remodel the taught muscle tissue. Such disorders promote local and systemic changes, contributing to coping with the inflammatory disorder of obese ED. Several variables imply the amplitude of the observed effects on the secretion of myokines and the production of cells of the immune system, in an acute and chronic way. It is possible to conclude that the different types of stimuli have different effects on the mentioned processes [51].

Several studies relate the sedentary lifestyle to the development of several types of cancers, such as breast cancer. There is strong evidence of myokines produced and released by skeletal muscle stimulated by physical exercise, they have an inhibitory action on the proliferation of cancer cells in breast mammary tissue. This effect has been attributed to oncostatin $\mathrm{M}$, another cytokine related to the IL-6 family. In general, sedentary lifestyle and physical inactivity lead to sarcopenia and the accumulation of visceral fat, resulting in the development of a chronic inflammatory process, which leads to conditions of resistance to the action of insulin, formation of atheroma plaques, neurodegeneration and tumor growth, among other disorders that promote the appearance and progression of several diseases [49].

\section{Conclusion}

Obesity presents with a low-grade chronic inflammation resulting from the sustained state of altered immune responses, promoting metabolic complications involved in the disease, such as insulin resistance, and favoring the development of several other diseases. The recommendation to practice physical exercises is supported by studies that satisfactorily demonstrate the benefits of physical exercise to fight obesity, due to the anti- inflammatory effects mediated by changes in the expression of myocins, genes and proteins that influence metabolism and functioning various systems. The benefits of physical exercises are dependent on regularity, however, it is not defined in the literature which values volume, intensity, or even what types of exercises are the most suitable for combating obesity. Therefore, it is necessary for each individual to practice physical exercises prescribed by Physical Educators, according to their own individualities.

\section{Conflict of Interest}

We declare that there is no conflict of interest in the development of this research.

\section{References}

1. Mushtaq MU, Gull S, Abdullah HM, Shahid U, Shad MA, et al. (2011) Prevalence and socioeconomic correlates of overweight and obesity among Pakistani primary school children. BMC Public Health 11: 2-8. [Crossref]

2. Huang H, Yan Z, Chen Y, Liu F (2016) A social contagious model of the obesity epidemic. Sci Rep 6: 2-6

3. World Health Organisation (1995) Physical Status: The use and interpretation of anthropometry. WHO Tech Rep Ser 854(Geneva WHO).

4. Sahoo K, Sahoo B, Choudhury AK, Sofi NY, Kumar R, et al. (2015) Childhood obesity: causes and consequences. J Fam Med Prim care 4:187-190. [Crossref]

5. Romieu I, Dossus L, Barquera S, Blottière HM, Franks PW, et al. (2017) Energy balance and obesity: what are the main drivers? Cancer Causes Control 28: 247-258. [Crossref]
6. World Health Organization (2017) Guideline: assessing and managing children at primary health-care facilities to prevent overweight and obesity in the context of the double burden of malnutrition. Updates for the Integrated Management of Childhood Illness (IMCI), Italy.

7. Erin EK, Jeffrey SF (2004) Adipose Tissue as an Endocrine Organ. The Journal of Clinical Endocrinology \& Metabolism 89: 2548-2556. [Crossref]

8. Tilg H, Moschen A (2006) Adipocytokines: mediators linking adipose tissue, inflammation and immunity. Nat Rev Immunol 6: 772-783. [Crossref]

9. Vigitel (2015) Estimativas Sobre Frequência E Distribuição Sociodemográfica De Fatores De Risco E Proteção Para Doenças Crônicas Nas Capitais Dos 26 Estados Brasileiros E No Distrito Federal Em 2015. SAUvDE SUPLEMENTAR. Brasília.

10. Gleeson M, Bishop N, Stensel D, Lindley MR, Mastana SS et al. (2011) The antiinflammatory effects of exercise: mechanisms and implications for the prevention and treatment of disease. Nat Rev Immunol 11: 607-615. [Crossref]

11. Souza S de A, Silva AB, Cavalcante UMB, Lima CMBL, Souza TC de (2018) Obesidade adulta nas nações: uma análise via modelos de regressão beta. Cad Saude Publica 34: 1-13.

12. Booth FW, Roberts CK, Laye MJ (2012) Lack of Exercise Is a Major Cause of Chronic Diseases. In Comprehensive Physiology 2: 1143-1199. [Crossref]

13. de Oliveira ML, Santos LMP, da Silva EN (2015) Direct Healthcare Cost of Obesity in Brazil: An Application of the Cost-of-Illness Method from the perspective of the Public Health System in 2011. PLoS ONE 10: 4-12. [Crossref]

14. OMS SINGH M (2015) Anthropometric measures during infancy and childhood and the risk of developing cardiovascular disease or diabetes mellitus type 2 in later life: A Systematic Review 85-92.

15. WHM (2017) WHO | Facts and figures on childhood obesity. World Health Organization.

16. Pietrobelli A, Faith MS, Allison DB, Gallagher D, Chiumello G, et al. (1998) Body mass index as a measure of adiposity among children and adolescents: A validation study. J Pediatr 132: 204-210. [Crossref]

17. Tavares TB, Nunes SM, Santos MDO (2010) Obesidade e qualidade de vida: revisão da literatura. Rev Med Minas Gerais 20: 359-66.

18. Agência Nacional De Saúde Suplementar (2017) 4. Abordagem Em Adultos. MANUAL DE DIRETRIZES PARA O ENFRENTAMENTO DA OBESIDADE NA SAÚDE SUPLEMENTAR BRASILEIRA; Brazil.

19. Sigrún Daníelsdóttir, Cand Psych, Deb Burgard, Wendy Oliver-Pyatt (2008) Diretrizes da Academy of Eating Disorders para Programas de Prevenção da Obesidade Infantil Sigrún. AED Guidelines for Childhood Obesity Prevention Programs.

20. Halpern A (1999) A epidemia de obesidade. Arquivos Brasileiros de Endocrinologia \& Metabologia 43: 175-176.

21. Francisqueti FV, Nascimento AFD, Corrêa CR (2015) Obesidade, inflamação e complicações metabólicas. Nutrire 81-89.

22. Prado WLD, Lofrano MC, Oyama LM, Dâmaso AR (2009) Obesidade e adipocinas inflamatórias: implicações práticas para a prescrição de exercício. Revista Brasileira de Medicina do Esporte 15: 378-383.

23. Panveloski-Costa AC, Júnior P, Correa DA, Brandão BB, Moreira RJ, et al. (2011) Treinamento resistido reduz inflamação em músculo esquelético e melhora a sensibilidade à insulina periférica em ratos obesos induzidos por dieta hiperlipídica. Arquivos Brasileiros de Endocrinologia \& Metabologia 55: 155-163.

24. Griffiths LJ, Parsons TJ, Hill AJ (2010) Self-esteem and quality of life in obese children and adolescents: A systematic review. Int J Pediatr Obes 5: 282-304. [Crossref]

25. Friedlander SL, Larkin EK, Rosen CL, Palermo TM, Redline S (2003) Decreased Quality of Life Associated With Obesity in School-aged Children. Arch Pediatr Adolesc Med 157: 1206-1211. [Crossref]

26. Schwimmer JB, Burwinkle TM, Varni JW (2003) Health-Related Quality of Life of Severely Obese Children and Adolescents. JAMA 289: 1813-1819. [Crossref]

27. Krinski K, Elsangedy HM, Colombo H, Buzzachera CF, Soares IA, et al. (2010) Physical exercise effects in the immunological system. RBM 67: 1-5.

28. Nutrition Education Society (2003) Guidelines for Childhood Obesity Prevention Programs: Promoting Healthy Weight in Children. Heal Weight J 17: 1-2. [Crossref]

29. World Health Organization (2010) Global recommendations on physical activity for health. World Health Organization. 
30. Karppanen AK, Ahonen SM, Tammelin T, Vanhala M, Korpelainen R (2012) Physical activity and fitness in 8-year-old overweight and normal weight children and their parents. International journal of circumpolar health 71: 1-9. [Crossref]

31. Utesch T, Dreiskämper D, Naul R, Geukes K (2018) Understanding physical (in) activity, overweight, and obesity in childhood: Effects of congruence between physical self-concept and motor competence. Scientific reports 8: 1-10.

32. Should W, Provide S, Activity P, Does H, Much H, et al. (2007) Youth Physical Activity: The Role of Schools 1-4.

33. Sartorelli DS, Franco LJ (2003) Tendências do diabetes mellitus no Brasil: o papel da transição nutricional. Cadernos de Saúde Pública 19: S29-S36.

34. Cong YJ, Gan Y, Sun HL, Deng J, Cao SY, et al. (2014) Associação de comportamento sedentário com câncer de cólon e retal: uma metanálise de estudos observacionais. British Journal of Cancer 110: 817-824.

35. Galic S, Oakhill JS, Steinberg GR (2010) Adipose tissue as an endocrine organ. Molecular and Cellular Endocrinology 316: 130-136. [Crossref]

36. Singer K, Lumeng CN (2017) The initiation of metabolic inflammation in childhood obesity. The Journal of clinical investigation 127: 65-73. [Crossref]

37. Wagenmakers AJ, Pedersen BK (2006) The anti-inflammatory effect of exercise: its role in diabetes and cardiovascular disease control. Essays in biochemistry 42: 105117. [Crossref]

38. Freitas MC (2016) Efeitos do treinamento resistido e do destreinamento na inflamação e expressão de genes do metabolismo muscular e tecido adiposo de ratos alimentados por dieta hiperlipídica. UNESP 57: 22-40.

39. Lacerda MS, Malheiros GC, Abreu A de OW de (2016) TECIDO ADIPOSO, UMA NOVA VISÃO: AS ADIPOCINAS E SEU PAPEL ENDÓCRINO. Revista Científica da Faculdade de Medicina de Campos 11:25-31.

40. Santos LC, Torrent IF (2010) The adipous tissue and the production of adipocines. SYNTHESIS| Revistal Digital FAPAM 2: 110-119.

41. Souza JRM, Oliveira R T, Blotta MHS, Coelho OR (2008) Serum levels of interleukin-6 (Il-6), interleukin-18 (Il-18) and C-reactive protein (CRP) in patients with type-2 diabetes and acute coronary syndrome without ST-segment elevation. Arquivos brasileiros de cardiologia 90: 86-90.
42. da Cruz Fernandes IM, Pinto RZ, Ferreira P, Lira FS (2018) Low back pain, obesity, and inflammatory markers: exercise as potential treatment. Journal of exercise rehabilitation 14: 168-172. [Crossref]

43. Ribeiro SML, Santos ZAD, Silva RJD, Louzada E, Donato Junior J, et al. (2007) Leptina: aspectos sobre o balanço energético, exercício físico e amenorréia do esforço. Arquivos Brasileiros de Endocrinologia \& Metabologia 51: 11-24.

44. Gomes F, Telo DF, Souza HP, Nicolau JC, Halpern A, (2010) Obesidade e doença arterial coronariana: papel da inflamação vascular. Arquivos brasileiros de cardiologia 94: 273-279.

45. Oda E (2008) The metabolic syndrome as a concept of adipose tissue disease. Hypertension Research 31: 1283-1288. [Crossref]

46. Sell VP, Da Cunha AF, Pitol G, Paulino R, Mostardeiro LR, (2019) ESTUDO DA PREVALÊNCIA DOS FATORES DE RISCO PARA AS DOENÇAS CRÔNICAS NÃO TRANSMISSÍVEIS (DCNT): AVALIAÇÃO DA PREVENÇÃO, MORBIDADE E MORTALIDADE, COM ABORDAGENS EM NUTRIÇÃO E SAÚDE COLETIVA. In $6^{\circ}$ Congresso Internacional em Saúde (No. 6).

47. Whitham M, Febbraio MA (2016) The ever-expanding myokinome: discovery challenges and therapeutic implications. Nature reviews Drug discovery 15: 1-9. [Crossref]

48. Meneguci J, Santos DAT, Silva RB, Santos RG, Sasaki JE, et al. (2015) Comportamento sedentário: conceito, implicações fisiológicas e os procedimentos de avaliação. Motricidade 11: 161-171.

49. Chen K, Zhou M, Wang X, Li S, Yang D (2019) The Role of Myokines and Adipokines in Hypertension and Hypertension-related Complications. Hypertension Research 42: 1544-1551. [Crossref]

50. Pedersen BK, Febbraio MA (2012) Muscles, exercise and obesity: skeletal muscle as a secretory organ. Nature Reviews Endocrinology 8: 457-465. [Crossref]

51. Petersen AMW, Pedersen BK (2005) The anti-inflammatory effect of exercise. Journal of applied physiology 98: 1154-1162. [Crossref]

52. Antunes BDM, Rossi FE, Inoue DS, Neto JCR, Lira FS (2017) Imunometabolismo e Exercício Físico: Uma nova fronteira do conhecimento. Motricidade 13: 85-95. 